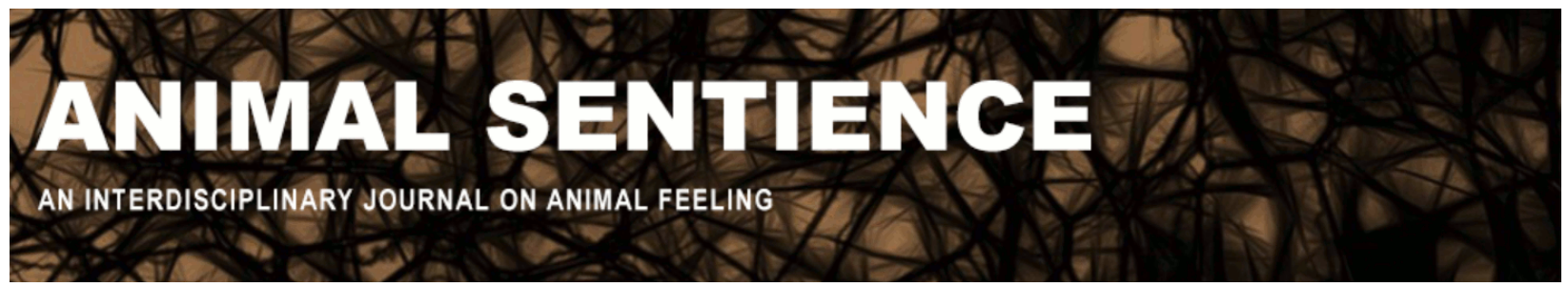

Tiffın, Helen (2019) Human interests. Animal Sentience 27(12)

DOI: $10.51291 / 2377-7478.1543$

Date of submission: 2020-01-12

Date of acceptance: 2020-01-15

(c) (i)

This article has appeared in the journal Animal

Sentience, a peer-reviewed journal on animal

cognition and feeling. It has been made open access,

free for all, by WellBeing International and deposited

in the WBI Studies Repository. For more information,

please contact

wbisr-info@wellbeingintl.org.

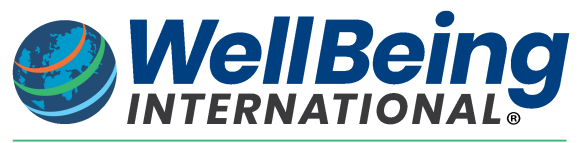

SOLUTIONS FOR PEOPLE, ANIMALS AND ENVIRONMENT 


\title{
Human interests
}

Commentary on Treves et al. on Just Preservation

\author{
Helen Tiffin \\ English and Animal Studies \\ University of Wollongong, Australia
}

\begin{abstract}
Treves et al.'s proposal is welcome, but it will have to face at least four challenges: the interconnectedness of the human and the nonhuman portions of the biosphere, conflicts of interest, human overpopulation, and capitalism itself.
\end{abstract}

\begin{abstract}
Helen Tiffin is Honorary Professor of English and Animal Studies at University of Wollongong and Fellow of the Rachel Carson Center for Environment and Society. Her most recent publications include Do Insects Feel Pain?, Wild Man from Borneo: A Cultural History of the Orangutan (with Robert Cribb and Helen Gilbert), and Ecocritical Concerns and the Australian Continent (London, Lexington, 2020; Beate Neumeier \& Helen Tiffin, Eds.). Website
\end{abstract}

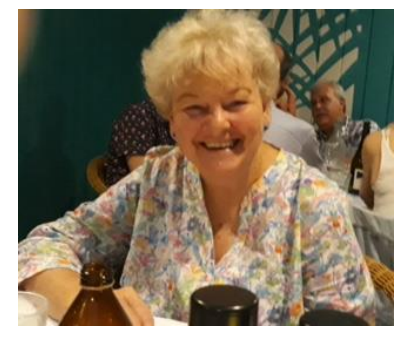

Treves et al.'s (2019) proposal has great merit, arguing as it does for a shift in current processes of decision making on the future of the planet - which are at present generally confined to adult humans with various vested interests - to include representation for nonhuman "selves", both as individuals and groups, and for young and future generation humans. They propose advocacy through a court system in which qualified "trustees" represent those who cannot represent themselves.

These suggestions thus entail radical rethinking of the popularly accepted Cartesian divide, and a reconstitution of the nature of "selves" entitled to rights under existing or future constitutional laws. In addition to the proposed changes in philosophy as well as legal and constitutional practices, I would suggest that further consideration needs to be given to the following.

1. Connectedness. The issue of connection - even the almost indispensable continuity of various selves - is implicit in Treves et al.'s proposal. In the case of humans and nonhumans, this probably needs more emphasis. Although nonhuman selves are perforce dependent on us, we humans are in many emotional, philosophical and material ways also dependent on them. Such continuity is stressed in studies of trophic cascades (e.g., Wohlleben (2017) as well as in all ecosystem studies. But human dependence on the nononhuman (or "extra-human": I prefer Plumwood's terminology) needs more consideration.

2. Conflicts of Interest. Treves et al. refer to "confusion" between the positions of advocates of wellbeing or rights for individual nonhumans, and the customary conservationist stance of an exclusionary prioritisation of groups or species. This, however, is less a confusion than an outright conflict - a stressful and complex issue for those who wish to effect a strategic 
alliance between the proponents of both (Sagoff, 1984). It has even generated virtually separate disciplines. Mathews (2012) points out that not only is this a conflict of philosophical positions: it bedevils practice in relation to the nonhuman on a number of fronts. She also traces the very different origins of the two positions. In treating this rift as confusion rather than conflict, Treves et al. gloss over a fundamental challenge for both theory and practice without really addressing it.

3. Population. Any future court arbitration attempting fair judgment for all stakeholders would need to assume some degree of a level playing field - or at least a field on which to play. But "habitat loss" already irretrievably incurred by nonhumans (and some humans as well) precludes a plethora of future possibilities. "Habitat loss" is a convenient passive euphemism for human annihilation, decimation, displacement and destruction of individual and group selves. This accelerating habitat loss can be addressed only through an open discussion and confrontation of the pandemic problem of human overpopulation. (Whereas human growth rates are declining in some countries, overall population numbers are not.) Once sentient selves, both human and nonhuman are present on the planet, their wellbeing and rights must be respected and attended to. The right to reproduce as much as they choose, however, is apparently unassailable and inalienable for all humans (though not nonhumans). This fraught subject must be broached if the planet is to offer any future at all for nonhumans (and, by continuity, to humans themselves).

4. Capitalism. Treves et al. do acknowledge the difficulty of challenging powerful capitalist interests in changing the very concept of "who counts" and implementing legislation to arbitrate competing positions. They do not see this as insurmountable, however, citing the abolition of the slave trade. It is certainly true that Europe's financial wealth was, for almost two centuries, heavily dependent on that trade. But its eventual abolition did not threaten capitalism itself, nor did it challenge the icons of "progress" and "development" - as the proposals of Treves et al. assuredly would. Capitalism, land grabbing, and wealth accumulation as the be-all and end-all of current human societies and individuals is no longer simply the province of the West: it is the goal of an expanding China, as well as of the many world communities that are still or increasingly under Western or Chinese influence.

\section{References}

Mathews, F. (2012). The anguish of wildlife ethics. New Formations, 76: 114-131.

Plumwood, V. (2005). Environmental culture: The ecological crisis of reason. Routledge. Sagoff, M. (1984). Animal liberation and environmental ethics: Bad marriage, quick divorce.

Osgoode Hall Law Journal, 22(2): 297-307.

Treves, A., Santiago-Ávila, F. J., \& Lynn, W. S. (2019). Just preservation. Animal Sentience 27(1). Wohlleben, P. (2017). The secret network of nature: The delicate balance of all living things.

London: Vintage. 


\section{PhD Scholarship in Foundations of Animal Sentience (ASENT) London School of Economics}

The Foundations of Animal Sentience project (ASENT), a five-year ERC-funded project led by Dr. Jonathan Birch, aims to study the methodological foundations of animal sentience research and the link between sentience and animal welfare. The project seeks to recruit one PhD student. The student will contribute to the project either by exploring the methodological foundations of animal sentience research, or by investigating the pathway from animal sentience research to consequences for animal welfare legislation and policy and/or animal ethics.

The student, at the time of starting the $\mathrm{PhD}$, should have an excellent undergraduate degree and a completed Masters degree in philosophy or another relevant subject, such as comparative psychology, cognitive science, or animal welfare science. The primary supervisor of the $\mathrm{PhD}$ project will be Dr. Jonathan Birch. If you have any questions or want to know more about the project, please write to Jonathan at j.birch2@lse.ac.uk.

The successful applicant will receive full funding for a 4-year PhD at the LSE, including full payment of tuition fees AND a maintenance stipend of $£ 18,000$ per annum. To apply, please apply to the MPhil/PhD in Philosophy at the LSE in the usual way, carefully following all the requirements described on the LSE's website: http://www.lse.ac.uk/study-atlse/Graduate/Degree-programmes-2020/MPhilPhD-Philosophy. When you apply, please indicate clearly in your application (in both your Statement of Academic Purpose AND your Research Proposal) that you wish to be considered for the ASENT scholarship.

You should include, in your research proposal, a substantial description (of at least 1,500 words) of a research project relevant to ASENT. You MAY, if you wish, include TWO research proposals in the same document: a proposal relevant to ASENT, and a proposal on a different subject that you would pursue if awarded an LSE Studentship or a LAHP (AHRC) scholarship. If you do this, please indicate clearly which of the two proposals is relevant to ASENT.

\section{CLOSING DATE: 24 JANUARY 2020.}

It is expected that interviews will be conducted in late January or in February.

www.lse.ac.uk/philosophy/asent-scholarship/ 